Morie A. Gertz, Mayo Clinic, Rochester, $\mathrm{MN}$; Heather Landau, Memorial Sloan Kettering Cancer Center, New York, NY; Raymond L. Comenzo, Tufts Medical Center; David Seldin, Boston University, Boston, MA; Brendan Weiss, University of Pennsylvania, Philadelphia, PA; Jeffrey Zonder, Karmanos Cancer Institute, Detroit, Ml; Giampaolo Merlini,

Fondazione Instituto Di Ricovero e Cura a Carattere Scientifico Policlinico San

Matteo and University of Pavia, Pavia, Italy; Stefan Schönland, University of Heidelberg, Heidelberg, Germany; Jackie Walling, JW Consulting, Hillsborough; Gene G. Kinney, Martin Koller, Dale B Schenk, and Spencer D. Guthrie, Prothena Biosciences, Inc., South San Francisco; and Michaela Liedtke, Stanford University School of Medicine, Stanford, CA

\section{tDeceased}

Published online ahead of print at www.jco.org on February 8, 2016.

Supported by Prothena Biosciences, Inc. South San Francisco, CA.

Presented at the International Symposium on Amyloidosis, Indianapolis, IN, April

27-May 1, 2014; the American Society for Clinical Oncology, Chicago, IL, May

29-June 2, 2015; and the European Hematology Association, Vienna, Austria, June 11-14, 2015.

Authors' disclosures of potential conflicts of interest are found in the article online at www.jco.org. Author contributions are found at the end of this article.

Corresponding author: Morie A Gertz, MD, Division of Hematology, Mayo Clinic, 200 First St SW, Rochester, MN 55905; e-mail: gertz.morie@mayo.edu.

() 2016 by American Society of Clinical Oncology

0732-183X/16/3410w-1097w/\$20.00

DOI: $10.1200 / J C 0.2015 .63 .6530$

\title{
First-in-Human Phase I/II Study of NEOD001 in Patients With Light Chain Amyloidosis and Persistent Organ Dysfunction
}

Morie A. Gertz, Heather Landau, Raymond L. Comenzo, David Seldin, $\dagger$ Brendan Weiss, Jeffrey Zonder, Giampaolo Merlini, Stefan Schönland, Jackie Walling, Gene G. Kinney, Martin Koller, Dale B. Schenk, Spencer D. Guthrie, and Michaela Liedtke

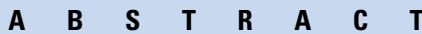

\section{Purpose}

Light chain $(A L)$ amyloidosis is caused by the accumulation of misfolded proteins, which induces the dysfunction of vital organs. NEOD001 is a monoclonal antibody targeting these misfolded proteins. We report interim data from a phase $\mathrm{I} / \mathrm{Il}$ dose-escalation/expansion study of NEOD001 in patients with AL amyloidosis and persistent organ dysfunction (NCT01707264).

\section{Patients and Methods}

Patients who had completed at least one previous anti-plasma cell-directed therapy, had partial hematologic response or better, and had persistent organ dysfunction received NEOD001 intravenously every 28 days. Dose levels of $0.5,1,2,4,8,16$, and $24 \mathrm{mg} / \mathrm{kg}$ were evaluated ( $3+3$ study design). Primary objectives were to determine the maximum tolerated dose and the recommended dose for future studies and to evaluate safety/tolerability. Secondary and exploratory objectives included pharmacokinetics, immunogenicity, and organ responses on the basis of published consensus criteria.

\section{Results}

Twenty-seven patients were enrolled in seven cohorts (dose-escalation component). No drugrelated serious adverse events (AEs), discontinuations because of drug-related AEs, dose-limiting toxicities, or antidrug antibodies were reported. The most frequent AEs were fatigue, upper respiratory tract infection, cough, and dyspnea. Recommended dosing was $24 \mathrm{mg} / \mathrm{kg}$. Pharmacokinetics support intravenous dosing every 28 days. Of 14 cardiac-evaluable patients, eight (57\%) met the criteria for cardiac response and six (43\%) had stable disease. Of 15 renal-evaluable patients, nine $(60 \%)$ met the criteria for renal response and six $(40 \%)$ had stable disease.

\section{Conclusion}

Monthly infusions of NEOD001 were safe and well tolerated. Recommended future dosing was $24 \mathrm{mg} / \mathrm{kg}$. Organ response rates compared favorably with those reported previously for chemotherapy. A phase II expansion is ongoing. A global phase III study (NCT02312206) has been initiated. Antibody therapy targeting misfolded proteins is a potential new therapy for the management of $A L$ amyloidosis.

\section{J Clin Oncol 34:1097-1103. (C) 2016 by American Society of Clinical Oncology}

\section{INTRODUCTION}

Systemic amyloidoses are a group of diseases characterized by the accumulation of abnormal, misfolded protein (amyloid) in tissues and organs. ${ }^{1}$ In immunoglobulin light chain (AL) amyloidosis, the most common form of systemic amyloidosis, ${ }^{1}$ the amyloidogenic protein is a misfolded light chain or light chain fragment produced by clonal plasma cells. ${ }^{1,2}$ Amyloid aggregates can affect multiple organs, including the heart (approximately 70\% of patients), kidneys (70\%), liver (17\%), soft tissue (17\%), nervous system (15\%), and gastrointestinal tract $(10 \%) .^{3-5}$ Amyloid accumulation progressively affects organ structure and function, ${ }^{2}$ but diagnosis is often delayed because subtle symptoms at onset mimic those of common conditions. ${ }^{2}$ For patients with cardiac amyloidosis, the extent of cardiac involvement is a major outcome determinant; most deaths are attributed to cardiac involvement, and survival is poor with advanced involvement. ${ }^{1,2,6}$ 
No therapies for $\mathrm{AL}$ amyloidosis have received regulatory approval, and optimal treatment regimens remain undefined. ${ }^{7,8}$ Options include high-dose chemotherapy with autologous stem cell transplant, alkylating agents, steroids, proteasome inhibitors, and immunomodulatory drugs. ${ }^{2,4,7}$ These treatments reduce the production of immunoglobulin light chain precursor proteins by targeting the plasma cells that synthesize them, but they do not directly address the soluble aggregates or the deposited amyloid. ${ }^{2,4,7}$ Although plasma cell-directed therapies may induce hematologic responses that result in organ improvement, the improvement achieved is highly variable and often incomplete. ${ }^{2,3,8}$ A critical unmet need in patients with AL amyloidosis is a therapy that directly targets soluble aggregates and amyloid protein deposits to improve organ function.

NEOD001, a humanized form of murine monoclonal antibody $2 \mathrm{~A} 4$, binds to an epitope unique to the misfolded light chain protein. The cryptic light chain epitope is thought to be exposed during misfolding and aggregation but is not available in light chain's native conformation or in fully formed immunoglobulin. ${ }^{9}$ Accordingly, 2A4 was shown to immunoreact with both soluble and insoluble light chain aggregates derived from samples from patients with AL while sparing normally folded light chain. In vivo, $2 \mathrm{~A} 4$ promoted $\mathrm{AL}$ amyloid clearance in a mouse amyloidoma model by engaging phagocytes. ${ }^{9}$ Therefore, NEOD001 is hypothesized to directly target and clear light chain amyloid deposited in affected organs of patients with AL, with the potential to restore organ function. We report interim results from the doseescalation component of an ongoing, first-in-human, phase I/II dose-escalation/expansion study of NEOD001 in patients with AL amyloidosis and persistent organ dysfunction.

\section{PATIENTS AND METHODS}

\section{Study Design}

This is an ongoing, phase I/II, open-label study of NEOD001 in patients with AL amyloidosis and persistent organ dysfunction (ClinicalTrials.gov NCT01707264; EudraCT 2012-002683-27). There are two components: (1) dose escalation to assess the safety/tolerability and to determine the maximum tolerated dose (MTD) and recommended dose of NEOD001 for future studies and (2) expansion to assess the safety, preliminary efficacy, and pharmacokinetics (PK) of NEOD001 administered at the recommended future dose. In the absence of confirmed organ dysfunction, unacceptable treatment-related toxicity, or withdrawal of consent, patients may receive NEOD001 for $\leq 1$ year at the investigator's discretion and for more than 1 year with the additional agreement of the sponsor. The study was conducted according to International Committee on Harmonization Good Clinical Practice guidelines. All patients provided informed consent.

\section{Patients}

Eligible patients were aged $\geq 18$ years and had diagnoses of $\mathrm{AL}$ amyloidosis and ongoing organ involvement, Eastern Cooperative Oncology Group performance status of 0 to 2, at least one previous plasma cell-directed therapy, and at least partial hematologic response to previous therapy. Patients in the dose-escalation component had to meet predefined definitions of systemic organ involvement (online only Appendix). Exclusion criteria included N-terminal pro-brain natriuretic peptide (NTproBNP) concentration of more than $5,000 \mathrm{pg} / \mathrm{mL}$, life expectancy of less than 3 months, and symptomatic multiple myeloma. Patients who required plasma cell-directed therapy were excluded.

\section{Treatments and Assessments}

The dose-escalation component followed a standard $3+3$ design, with cohorts of three to six patients enrolled at each dose level. NEOD001 was administered intravenously once every 28 days. The starting dose was $0.5 \mathrm{mg} / \mathrm{kg}$ and, once deemed safe and well tolerated, this was increased to 1 , $2,4,8,16$, and $24 \mathrm{mg} / \mathrm{kg}$. Dose escalation was to proceed to $30 \mathrm{mg} / \mathrm{kg}$ (or an absolute maximum of 2,500 mg, whichever was lower). However, a dose of $24 \mathrm{mg} / \mathrm{kg}$ was selected for cohort 7 (the highest dose level studied). On the basis of body weights (cohorts 1 to 6 ), a significant number of patients would have reached the absolute maximum dose of 2,500 $\mathrm{mg}$ with doses greater than $24 \mathrm{mg} / \mathrm{kg}$. The selection of $24 \mathrm{mg} / \mathrm{kg}$ as the cohort 7 dose allowed a greater number of patients to be dosed on an $\mathrm{mg} / \mathrm{kg}$ basis rather than at the absolute maximum dose of 2,500 mg. Patients enrolled at the original 1 and $24 \mathrm{mg} / \mathrm{kg}$ dose levels were expanded from 3 to 6 patients to assess safety and PK (six patients per dose level). Each patient participated in only one dose-level cohort, but the dosage could be increased to $24 \mathrm{mg} / \mathrm{kg}$ at the discretion of the investigator once $24 \mathrm{mg} / \mathrm{kg}$ was selected as the recommended dose for future study (if the patient had received NEOD001 at a lower dose for at least three infusions without experiencing dose-limiting toxicities [DLTs]).

The primary objectives of the dose-escalation component were to determine the MTD and the recommended dose for future studies and to evaluate the safety and tolerability of intravenous NEOD001 administered every 28 days. Secondary objectives included evaluation of the PK and immunogenicity of NEOD001. Assessment of hematologic and organ responses and correlation of changes in serum biomarkers of organ function with NEOD001 exposure levels were exploratory end points. MTD was defined as the highest dose level at which no more than one of six patients experienced a DLT during the first month of therapy (Appendix). The recommended future dose was based on toxicities and on biologic, pharmacologic, and clinical activities noted, up to the maximum dose level tested (if MTD was not reached at the maximum dose level).

Adverse events (AEs) were graded according to National Cancer Institute Common Terminology Criteria for Adverse Events v4.0. Cardiac response was assessed using previously described criteria ${ }^{10}$ (Appendix). Renal response was assessed using the Palladini et $\mathrm{al}^{5}$ criteria (Appendix).

Blood samples for PK analysis were obtained for months 1 and 3 before the start of an infusion (baseline) and immediately after infusion, at $0.5,1,2$, and 4 hours and at 1,8 , and 15 days after infusion.

\section{Statistical Analyses}

Demographic and baseline characteristics were summarized using descriptive statistics. Safety was assessed through summaries of AEs, changes in laboratory test values, and vital signs. Serum antidrug antibody titers were correlated with PK values and clinical toxicity. Individual and mean serum NEOD001 concentrations at each sampling time were summarized by dose level. PK parameters were calculated from serum NEOD001 concentrations using noncompartmental techniques, and exploratory assessments for dose proportionality were performed. Hematologic and organ (heart, kidney, liver) response assessment data were listed for all patients by assigned dose, and rates were calculated by assigned dose. Hematologic response was monitored according to the standard of care. For a specific organ, the corresponding response rate was assessed only in patients who had had involvement of that organ at screening.

\section{RESULTS}

\section{Patient Characteristics}

Twenty-seven patients enrolled at seven clinical sites were included in the dose-escalation component of this study, comprising seven dose cohorts: $0.5 \mathrm{mg} / \mathrm{kg}(\mathrm{n}=3), 1 \mathrm{mg} / \mathrm{kg}(\mathrm{n}=6), 2 \mathrm{mg} / \mathrm{kg}(\mathrm{n}=$ 3), $4 \mathrm{mg} / \mathrm{kg}(\mathrm{n}=3), 8 \mathrm{mg} / \mathrm{kg}(\mathrm{n}=3), 16 \mathrm{mg} / \mathrm{kg}(\mathrm{n}=3)$, and $24 \mathrm{mg} / \mathrm{kg}$ 
$(n=6)$. Patient characteristics are summarized in Table $1 ; 18$ patients $(66.7 \%)$ were male, and the median time since initial diagnosis was 2.5 years. All patients had received previous systemic therapy; 10 of $27(37 \%)$ received two to three and five of $27(18.5 \%)$ received at least three previous plasma cell-directed therapies. Twenty-one (77.8\%) had previously received bortezomib. The best hematologic response across all previous systemic therapies was complete response (CR), very good partial response (VGPR), and partial response (PR) in 14 patients $(51.9 \%)$, seven patients $(25.9 \%)$, and three patients (11.1\%), respectively. The best hematologic response to the most recent systemic treatment was $\mathrm{CR}$, VGPR, and $\mathrm{PR}$ in 12 patients (44.4\%), five patients (18.5\%), and four patients (14.8\%), respectively.

All patients were escalated to $24 \mathrm{mg} / \mathrm{kg}$ as of December 2, 2014. As of the February 28, 2015, data cutoff date, 11 of the 27 enrolled patients had discontinued the dose-escalation phase of the study. Discontinuations were either protocol required (organ progression in four patients [one each in the $0.5,2,4$, and $8 \mathrm{mg} / \mathrm{kg}$ dose cohorts] and hematologic progression in one patient $[0.5 \mathrm{mg} /$ $\mathrm{kg}$ cohort]) or nonprotocol required/voluntary (patient decision in five cases [two in the $1 \mathrm{mg} / \mathrm{kg}$ cohort and one each in the 2, 16, and $24 \mathrm{mg} / \mathrm{kg}$ cohorts] and one patient death [24 mg/kg cohort]). Travel was a contributing factor in most voluntary discontinuations. Three patients who withdrew from the study did not complete the 30-day follow-up period (one was lost to follow-up [1 mg/kg cohort], one died [24 mg/kg cohort], and one returned to local oncologist to receive chemotherapy [ $24 \mathrm{mg} / \mathrm{kg}$ cohort]); all remaining patients who withdrew completed the 30-day followup period.

\section{Dosing}

The median number of 28-day treatment periods entered for the overall population in the dose-escalation phase of the study was 12 (range, four to 24). The total number of infusions administered was 327.

\section{Safety}

NEOD001 was well tolerated. All patients reported at least one treatment-emergent AE (TEAE); the most commonly reported of any severity were fatigue (10 patients; $37.0 \%)$, upper respiratory tract infection (seven patients; 25.9\%), cough (five patients; $18.5 \%$ ), dyspnea (five patients; 18.5\%), anemia (four patients; $14.8 \%$ ), increased blood creatinine (four patients; $14.8 \%$ ), headache (four patients; 14.8), and peripheral edema (four patients; $14.8 \%$ ), as shown in Table 2. AEs did not seem to be infusion related (did not appear shortly after infusion and were not correlated with treatment duration).

In an analysis of TEAEs occurring in $\geq 5 \%$ of patients (all NEOD001 doses), the occurrence of grade 3 and 4 events was limited to two cases of grade 3 hyponatremia and one case each of diverticulitis and pneumonia, which were not related to NEOD001. Twelve patients $(44.4 \%)$ reported TEAEs related to the study drug. No TEAEs of grade 3 or higher and no serious TEAEs were related to the study drug. One patient in the $24 \mathrm{mg} / \mathrm{kg}$ dose group died. This patient had an NT-proBNP value of 3,958 pg/mL before the first NEOD001 infusion and received 10 months of NEOD001 before death. Serial NT-proBNP values were 4,053 (infusion 2),

\begin{tabular}{|c|c|}
\hline Characteristic & Value \\
\hline Total patients, No. & 27 \\
\hline Median age (range), years & $60(38-80)$ \\
\hline Male, No. (\%) & $18(66.7)$ \\
\hline \multicolumn{2}{|l|}{ Race, No. (\%) } \\
\hline White & $23(85.2)$ \\
\hline Black or African American & $1(3.7)$ \\
\hline Asian & $1(3.7)$ \\
\hline Unknown & $2(7.4)$ \\
\hline $\begin{array}{l}\text { Time since initial diagnosis, median (range), } \\
\text { years }\end{array}$ & $2.46(0.7-12.9)$ \\
\hline \multicolumn{2}{|l|}{$\begin{array}{l}\text { Physician-determined organs involved at } \\
\text { baseline (by physical evaluation), No. (\%) }\end{array}$} \\
\hline 1 & $9(33.3)$ \\
\hline 2 & 9 (33.3) \\
\hline$\geq 3$ & $9(33.3)$ \\
\hline \multicolumn{2}{|l|}{$\begin{array}{l}\text { Physician-determined organ involvement at } \\
\text { baseline (by physical evaluation), No. (\%) }\end{array}$} \\
\hline Renal & $19(70.4)$ \\
\hline Cardiac & $18(66.7)$ \\
\hline Hepatic & $3(11.1)$ \\
\hline Peripheral nervous system & $3(11.1)$ \\
\hline Gastrointestinal & $6(22.2)$ \\
\hline Autonomic nervous system & $1(3.7)$ \\
\hline Soft tissue/lymphatic & $4(14.8)$ \\
\hline Other involvement & $2(7.4)$ \\
\hline \multicolumn{2}{|l|}{$\begin{array}{l}\text { Baseline NT-proBNP, median (lower Q, upper Q), } \\
\mathrm{pg} / \mathrm{mL}\end{array}$} \\
\hline All patients $(n=27)$ & $651(160,1,129)$ \\
\hline Evaluable patients $(n=14)$ & $1,102.5(866.75,2,250.75)$ \\
\hline Responders $(n=8)$ & $1,768.5(1,089,2,456)$ \\
\hline \multicolumn{2}{|c|}{$\begin{array}{l}\text { Baseline proteinuria, median (lower } \mathrm{Q} \text {, upper } \mathrm{Q} \text { ), } \\
\mathrm{mg} / 24 \text { hours }\end{array}$} \\
\hline All patients $(n=23)^{*}$ & $3,134(163,6,112.5)$ \\
\hline Evaluable patients $(n=14)$ & $5,189.5(3,354.5,6,749)$ \\
\hline Responders $(n=9)$ & $4,834(3,002,6,049)$ \\
\hline \multicolumn{2}{|l|}{$\begin{array}{l}\text { Previous plasma cell-directed treatments, No. } \\
(\%)\end{array}$} \\
\hline Chemotherapy, alkylating agent & $23(85.2)$ \\
\hline Proteasome inhibitor & $21(77.8)$ \\
\hline IMiD & $4(14.8)$ \\
\hline Steroid & $21(77.8)$ \\
\hline Autologous transplantation & $8(29.6)$ \\
\hline Other & $4(14.8)$ \\
\hline $\begin{array}{l}\text { No. previous plasma cell-directed treatments, } \\
\text { median (range) }\end{array}$ & $2(1-7)$ \\
\hline \multicolumn{2}{|l|}{$\begin{array}{l}\text { Best hematologic response across all previous } \\
\text { plasma cell-directed treatments, No. }(\%)\end{array}$} \\
\hline Complete response & $14(51.9)$ \\
\hline VGPR & 7 (25.9) \\
\hline Partial response & $3(11.1)$ \\
\hline No response & 0 \\
\hline Progressive disease & 0 \\
\hline Unknown & $3(11.1)$ \\
\hline Not assessed & 0 \\
\hline \multicolumn{2}{|l|}{$\begin{array}{l}\text { Best hematologic response to most recent } \\
\text { plasma cell-directed treatments, No. (\%) }\end{array}$} \\
\hline Complete response & $12(44.4)$ \\
\hline VGPR & 5 (18.5) \\
\hline Partial response & $4(14.8)$ \\
\hline No response & $2(7.4)$ \\
\hline Progressive disease & 0 \\
\hline Unknown & $3(11.1)$ \\
\hline Not assessed & $1(3.7)$ \\
\hline
\end{tabular}

Abbreviations: IMiD, immunomodulatory drug; NT-proBNT, N-terminal pro-brain natriuretic peptide; $Q$, quartile; VGPR, very good partial response.

*Baseline was not assessable in four patients because baseline levels were below the level of assay quantitation $(n=3$ ) or because of an inability to collect the urine sample $(n=1)$. 


\begin{tabular}{|c|c|c|}
\hline \multirow{2}{*}{$\begin{array}{c}\text { AEs (Preferred Term) } \\
\text { ( } \geq 5 \% \text { Total Incidence) }\end{array}$} & \multicolumn{2}{|c|}{ All Patients $(\mathrm{N}=27)$} \\
\hline & Total AEs & Grade 3 or Higher AEs \\
\hline Fatigue & $10(37.0)$ & 0 \\
\hline Upper respiratory tract infection & 7 (25.9) & 0 \\
\hline Cough & $5(18.5)$ & 0 \\
\hline Dyspnea & $5(18.5)$ & 0 \\
\hline Headache & $4(14.8)$ & 0 \\
\hline Anemia & $4(14.8)$ & 0 \\
\hline Peripheral edema & $4(14.8)$ & 0 \\
\hline Increased blood creatinine & $4(14.8)$ & 0 \\
\hline Diarrhea & $3(11.1)$ & 0 \\
\hline Edema & $3(11.1)$ & 0 \\
\hline Nausea & $3(11.1)$ & 0 \\
\hline Hyponatremia & $3(11.1)$ & $2(7.4)$ \\
\hline Infusion site reaction & $2(7.4)$ & 0 \\
\hline Dyspnea exertional & $2(7.4)$ & 0 \\
\hline Oropharyngeal pain & $2(7.4)$ & 0 \\
\hline Productive cough & $2(7.4)$ & 0 \\
\hline Upper airway cough syndrome & $2(7.4)$ & 0 \\
\hline Wheezing & $2(7.4)$ & 0 \\
\hline Diverticulitis & $2(7.4)$ & $1(3.7)$ \\
\hline Pneumonia & $2(7.4)$ & $1(3.7)$ \\
\hline Arthralgia & $2(7.4)$ & 0 \\
\hline Back pain & $2(7.4)$ & 0 \\
\hline Dizziness & $2(7.4)$ & 0 \\
\hline Thrombocytopenia & $2(7.4)$ & 0 \\
\hline Depression & $2(7.4)$ & 0 \\
\hline Insomnia & $2(7.4)$ & 0 \\
\hline \multicolumn{3}{|c|}{$\begin{array}{l}\text { NOTE. Ten patients (37.0\%) reported a TEAE of grade } 3 \text { or higher, which } \\
\text { included colitis, gastroenteritis, syncope, hypertriglyceridemia, fall, hyper- } \\
\text { tension, noncardiac chest pain, diverticulitis, pneumonia, disseminated herpes } \\
\text { zoster, and large diffuse B-cell lymphoma (grade } 3 \mathrm{AE} \text { in one patient [3.7\%] } \\
\text { each), hyponatremia (grade } 3 \mathrm{AE} \text { in two patients [7.4\%]), intracardiac thrombus } \\
\text { and spleen rupture (grade } 4 \mathrm{AE} \text { in one patient [3.7\%] each), and death (grade } 5 \text { in } \\
\text { one patient [3.7\%]). } \\
\text { Abbreviation: } \mathrm{AE} \text {, adverse event; TEAE, treatment-emergent adverse event. }\end{array}$} \\
\hline
\end{tabular}

2,688 (infusion 3), 2,687 (infusion 4), 2,514 (infusion 5), 2,958 (infusion 6), 2,969 (infusion 7), 3,514 (infusion 8), 1,660 (infusion 9), and 2,769 (infusion 10). The investigators at all study sites agreed that this death was not related to the study drug. No patients required dose reductions because of a TEAE, but five patients $(18.5 \%)$ required interruption of study dosing because of TEAEs unrelated to the study drug. No DLTs were observed among the NEOD001 doses examined (up to $24 \mathrm{mg} / \mathrm{kg}$ ), and no antidrug antibodies or hypersensitivity reactions were observed.

\section{Cardiac and Renal Responses}

Cardiac and renal responses were exploratory end points (assessed on day 1 before each infusion). Change from baseline in cardiac-evaluable patients (baseline NT-proBNP $\geq 650 \mathrm{pg} / \mathrm{mL}$; $\mathrm{n}=14$ ) is presented in Figure 1 as a waterfall plot of best response analysis. Among cardiac-evaluable patients, eight (57\%) met the criteria for cardiac response and six $(43 \%)$ had stable disease. In cardiac responders, the median (lower quartile [Q], upper Q) NT-proBNP decreased from $1,768.5(1,089,2,456) \mathrm{pg} / \mathrm{mL}$ at baseline to $1,054(349,1,416) \mathrm{pg} / \mathrm{mL}$ at the best response assessment. The mean decrease from baseline was $-890 \mathrm{pg} / \mathrm{mL}$, which represented a $48 \%$ reduction and was statistically significant $(P<.008)$ using the Wilcoxon matched-pairs signed rank test. The NT-proBNP decline

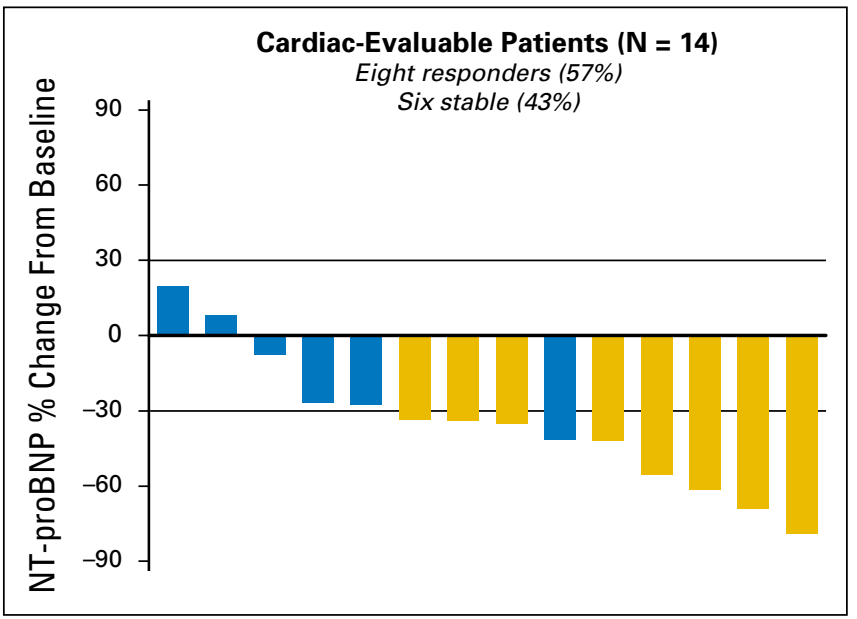

Fig 1. Best response analysis of percentage change in NT-proBNP from baseline in cardiac-evaluable patients (baseline NT-proBNP $\geq 650 \mathrm{pg} / \mathrm{mL}$ ). Responders are identified with gold bars (cardiac response was defined as $>30 \%$ and $300 \mathrm{pg} / \mathrm{mL}$ decrease in NT-proBNP, and cardiac progression was defined as $>$ $30 \%$ and $300 \mathrm{pg} / \mathrm{mL}$ increase in NT-proBNP in patients without progressive renal dysfunction and with baseline NT-proBNP $\geq 650 \mathrm{pg} / \mathrm{mL}$ ). Patients with stable disease are identified with blue bars (stable disease was defined as neither response nor progression). NT-proBNP, N-terminal pro-brain natriuretic peptide.

for responders correlated significantly with the increased number of NEOD001 infusions $(r=-0.45 ; P<.0001)$. New York Heart Association class improved from II to I in two cardiac responder patients (vs one nonresponder), worsened in one responder, and did not change in the remainder (four vs 15 nonresponders).

Change from baseline in proteinuria for renal-evaluable patients (baseline proteinuria $\geq 0.5 \mathrm{~g} / 24$ hours; $\mathrm{n}=15$ ) is presented in Figure 2 as a best response analysis. Note that baseline was not assessable in four patients because baseline levels were below the level of assay quantitation $(n=3)$ or because of an inability to collect the urine sample $(n=1)$. Among renalevaluable patients, nine $(60 \%)$ met the criteria for renal response and six (40\%) had stable disease. In the nine responders, the median (lower Q, upper Q) proteinuria value decreased from $4,834(3,002,6,049) \mathrm{mg} / 24$ hours at baseline to $1,647(544,2,783)$ $\mathrm{mg} / 24$ hours at the best response assessment. The mean decrease from baseline was $-2,647 \mathrm{mg} / 24$ hours, which represented a $62 \%$ decrease and was statistically significant $(P<.004)$ using the Wilcoxon matched-pairs signed rank test. Albumin was unchanged or marginally reduced $(3.4 \%$ to $4.5 \%)$ in most (seven of nine) renal responders (final measurement) compared with the baseline value. In two responders, serum albumin increased but remained below $4.0 \mathrm{~g} / \mathrm{dL}$ (final assessment). Pretreatment estimated glomerular filtration rate was in the normal range in seven patients. In the two patients with a reduced screening estimated glomerular filtration rate, final measurements were increased by $7.7 \%$ in one patient and reduced by $12.8 \%$ in the other, compared with baseline.

The median (range) number of previous therapies was one (one to three) among cardiac responders and three (one to four) among renal responders. Two patients had both cardiac and renal responses. Of the remaining responders, six and seven patients had renal or cardiac responses, respectively (12 patients had 


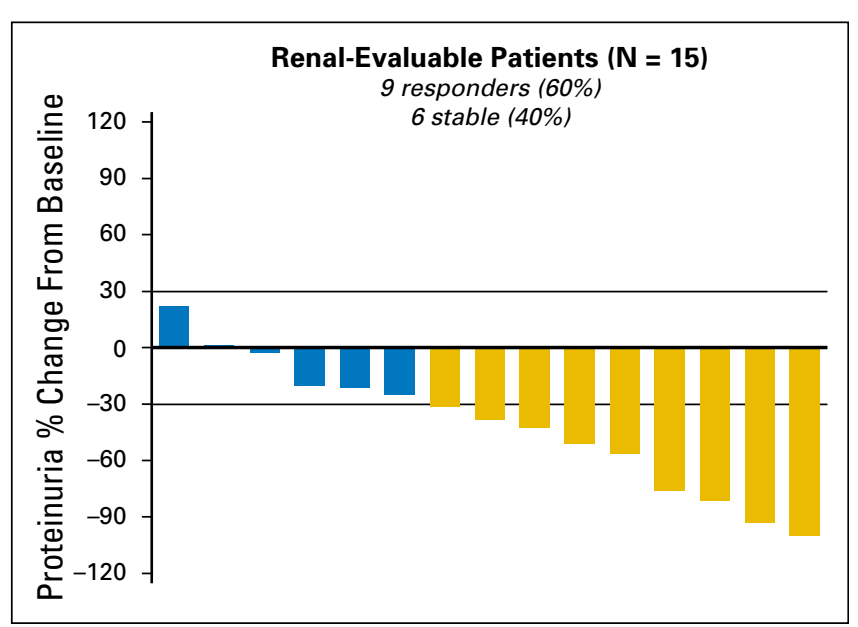

Fig 2. Best response analysis of percentage change in proteinuria from baseline in renal-evaluable patients (baseline proteinuria $\geq 0.5 \mathrm{~g} / 24 \mathrm{~h}$ ). Responders are identified with gold bars (renal response was defined as a $\geq 30 \%$ decrease in proteinuria or a decrease in proteinuria to $<0.5 \mathrm{~g} / 24 \mathrm{~h}$ in the absence of renal progression, defined as $>25 \%$ worsening in estimated glomerular filtration rate, for patients with baseline proteinuria $\geq 0.5 \mathrm{~g} / 24 \mathrm{~h}$ ). Patients with stable disease are identified with blue bars (stable disease was defined as neither response nor progression).

neither cardiac nor renal response). Durations of time at first NEOD001 treatment since best previous hematologic response and last hematologic response for cardiac and renal responders and nonresponders are presented in Table 3. Among responders, the best hematologic response for cardiac amyloidosis was CR 3, VGPR 5, and PR 0. For renal amyloidosis the best hematologic response was CR 4, VGPR 2, and PR 3.

\section{Pharmacokinetics}

Mean serum NEOD001 concentration-time profiles (months 1 and 3) are shown in Figure 3. No nonlinear accumulation of NEOD001 was observed over the dosing range. The terminal elimination half-life of NEOD001 in serum was approximately 13 to 16 days. The PK of NEOD001 is consistent with dosing by intravenous infusion every 28 days across the dose range.

\section{DISCUSSION}

In this first-in-human, dose-escalation, phase I/II study, NEOD001 was safe and well tolerated. No DLTs were observed at doses up to $24 \mathrm{mg} / \mathrm{kg}$ every 28 days. No drug-related serious AEs or hypersensitivity reactions were reported, and no antidrug antibodies were detected. The most frequent AEs were fatigue, upper respiratory tract infection, cough, and dyspnea, with the vast majority mild or moderate (grade 1/2). Monthly intravenous infusion of $24 \mathrm{mg} / \mathrm{kg}$ was identified as the recommended future dose. The ongoing expansion component of this study will enroll approximately 40 additional patients with AL amyloidosis and persistent organ dysfunction. The PK profile of NEOD001 was consistent with the expected behavior of a monoclonal antibody, ${ }^{11}$ with a mean terminal elimination half-life of approximately 13 to 16 days and no unexpected drug accumulation, which supports dosing once every 28 days.

$\mathrm{AL}$ amyloidosis remains an incurable disease associated with significant morbidity and mortality. ${ }^{6,12}$ Although there are no approved therapies for this disease, current options include antimyeloma-based treatments that target the plasma cells producing light chains. ${ }^{7,8}$ However, these therapies do not address the soluble and/or accumulated light chains deposited in organs or the poor outcomes that result from this accumulation. ${ }^{6,7}$

Because prognosis is determined largely by cardiac involvement and a significant number of patients die as a result of cardiac dysfunction without experiencing sufficient benefit from hematologic treatment, ${ }^{12,13}$ responses must translate into improved cardiac function. In $\mathrm{AL}$ amyloidosis patients, validated cardiac response criteria have enhanced patient care. NT-proBNP has been validated as a cardiac biomarker, and decreasing NT-proBNP levels predict lower mortality rates. ${ }^{10} \mathrm{NT}$-proBNP can also be used for early assessment of cardiac response, allowing treatment modification. ${ }^{5}$ In this study, monthly infusions of NEOD001 resulted in clinically meaningful reductions in NT-proBNP. Among cardiacevaluable patients, eight (57\%) had a response and six (43\%) had stable disease according to consensus criteria. ${ }^{10}$ These results compare favorably with historical data sets. In a previous systematic study of 377 treatment-naive patients with AL amyloidosis

\begin{tabular}{|c|c|c|c|c|}
\hline \multirow[b]{2}{*}{ Response Time } & \multicolumn{2}{|c|}{ Cardiac } & \multicolumn{2}{|c|}{ Renal } \\
\hline & $\begin{array}{l}\text { Responders } \\
\quad(\mathrm{n}=8)\end{array}$ & $\begin{array}{l}\text { Nonresponders } \\
\qquad(\mathrm{n}=6)\end{array}$ & $\begin{array}{l}\text { Responders } \\
\quad(\mathrm{n}=6)^{*}\end{array}$ & $\begin{array}{l}\text { Nonresponders } \\
\quad(\mathrm{n}=5) \dagger\end{array}$ \\
\hline \multicolumn{5}{|c|}{$\begin{array}{l}\text { Time at first treatment of NEOD001 since best previous } \\
\text { hematologic response, months }\end{array}$} \\
\hline Median & 8.53 & 6.18 & 3.9 & 4.2 \\
\hline Mean & 24.17 & 10.39 & 26.6 & 25.5 \\
\hline Range & $2.2-127.9$ & $1.2-23.8$ & $1.2-127.9$ & $1.5-89.8$ \\
\hline \multicolumn{5}{|c|}{$\begin{array}{l}\text { Time at first treatment of NEOD001 since last previous } \\
\text { hematologic response, months }\end{array}$} \\
\hline Median & 7.43 & 3.47 & 3.9 & 4.2 \\
\hline Mean & 9.9 & 8.69 & 10.9 & 14 \\
\hline Range & $2.2-20.63$ & $1.2-27.2$ & $1.17-40.3$ & $1.5-32.4$ \\
\hline
\end{tabular}




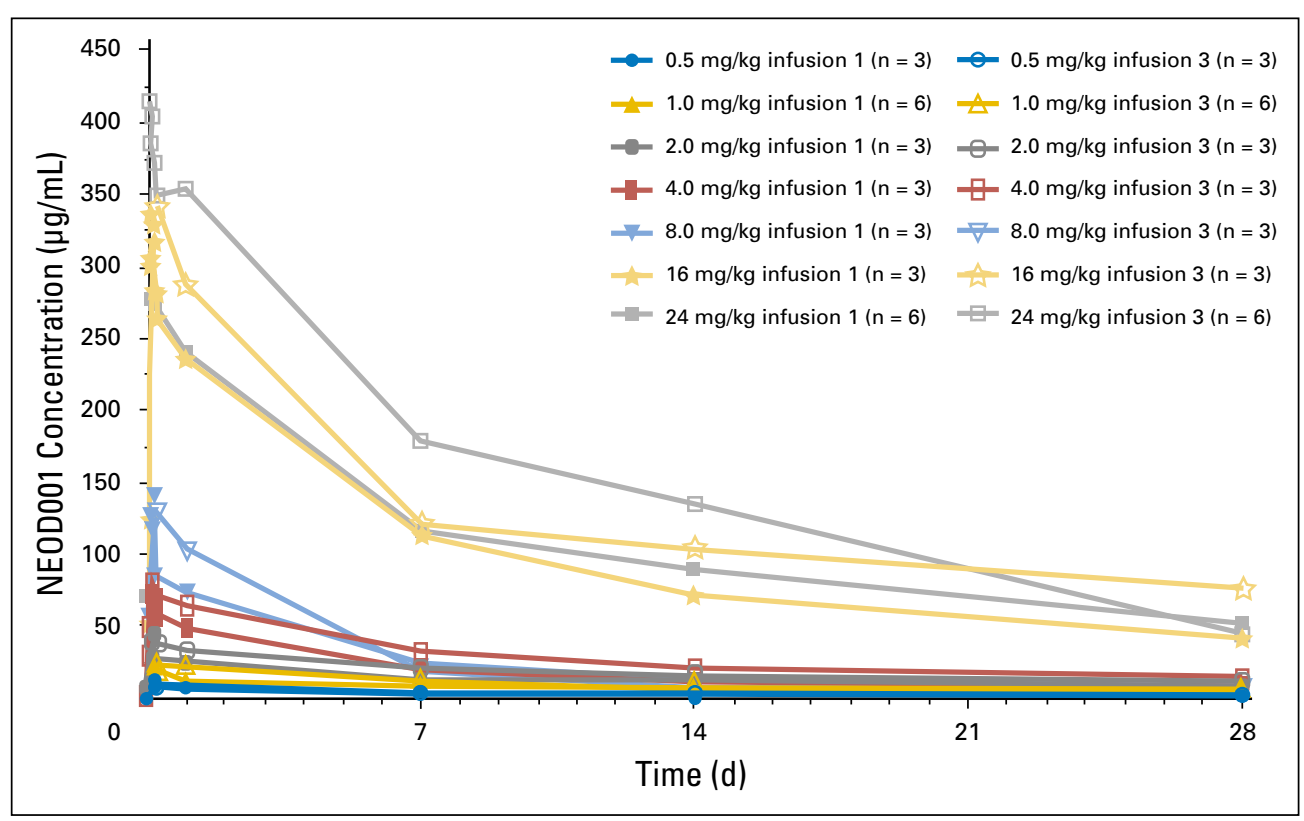

Fig 3. Mean serum NEOD001 concentrationtime profiles at infusions 1 and 3 .

and baseline NT-proBNP $\geq 650 \mathrm{pg} / \mathrm{mL}, 100$ (26.5\%) had cardiac response, $108(28.7 \%)$ had stable disease, and 169 (44.8\%) had progressive disease ${ }^{10,14}$ after plasma cell-targeted treatment.

On the basis of consensus renal criteria, ${ }^{5}$ nine renal-evaluable patients $(60 \%)$ had a response and six $(40 \%)$ had stable disease. These results compare favorably with organ response rates reported after intervention with standard of care in plasma cell-directed treatments. $^{3,6,15-21}$ A study of treatment-naive patients with $\mathrm{AL}$ amyloidosis with renal involvement evaluated 3 months after plasma cell-directed therapy demonstrated renal responses for 47 patients (23.3\%), stable disease for 89 patients $(44.1 \%)$, and progressive disease for 66 patients $(32.7 \%)$. Evaluations at 6 months included renal response for 115 patients $(24.4 \%)$, stable disease for 171 patients $(36.2 \%)$, and progression for 186 patients $(39.4 \%)$.

It should be noted that patients had at least partial hematologic response to previous plasma cell-directed therapy during which organ responses may be expected. A delayed organ response to previous chemotherapy could have confounded the interpretation of organ responses to NEOD001. It seems unlikely that this can adequately explain the data described herein. Patients enrolled were required to demonstrate organ dysfunction despite previous plasma cell-directed therapies, and no decline was observed in NT-proBNP before the administration of NEOD001 in those patients with multiple baseline assessments (Appendix Table A1, online only). There did not seem to be any discernible relationship between time since or degree of previous hematologic response (no differences in NEOD001 responders vs nonresponders) that could explain the NEOD001 responses. Finally, the observed rates of change in this study compared favorably with those reported in published data, although these intent-to-treat analyses included patients who died early as a result of amyloidosisrelated factors or who did not respond to chemotherapy. The design of this study effectively removed such patients from the denominator, which may be expected to affect observed organ response rates. ${ }^{22}$ On the basis of the positive results reported herein, a global phase III trial (NCT02312206) has been initiated.
Patients with amyloidosis treated with an anti-serum amyloid $\mathrm{P}$ component experienced an acute-phase response. ${ }^{23}$ Serum amyloid $\mathrm{P}$ plays a role in regulating inflammation and setting the threshold for immune cell activation. ${ }^{24,25}$ NEOD001 specifically targets the toxic amyloidogenic light chain. It should be noted that none of the patients treated with NEOD001 experienced an acute-phase response.

NEOD001 is safe and well tolerated in patients with AL amyloidosis and persistent organ dysfunction and has a PK profile supporting dosing once every 28 days. The phase II expansion component is ongoing at the recommended dose of $24 \mathrm{mg} / \mathrm{kg}$ every 28 days. Exploratory analyses suggest promising organ response rates using published consensus criteria. Antibody therapy targeting misfolded light chains may represent a new therapeutic platform for the management of AL amyloidosis.

\section{AUTHORS' DISCLOSURES OF POTENTIAL CONFLICTS OF INTEREST}

Disclosures provided by the authors are available with this article at www.jco.org.

\section{AUTHOR CONTRIBUTIONS}

Conception and design: Heather Landau, Giampaolo Merlini, Stefan Schönland, Gene G. Kinney

Provision of study materials or patients: Morie A. Gertz

Collection and assembly of data: Heather Landau, Raymond L. Comenzo, David Seldin, Brendan Weiss, Jackie Walling, Gene G. Kinney, Martin

Koller, Spencer D. Guthrie, Michaela Liedtke

Data analysis and interpretation: Morie A. Gertz, Raymond L. Comenzo, David Seldin, Brendan Weiss, Jeffrey Zonder, Jackie Walling, Gene G. Kinney, Martin Koller, Dale B. Schenk, Spencer D. Guthrie, Michaela Liedtke

Manuscript writing: All authors

Final approval of manuscript: All authors 


\section{REFERENCES}

1. Sanchorawala V: Light-chain (AL) amyloidosis: Diagnosis and treatment. Clin J Am Soc Nephrol 1: 1331-1341, 2006

2. Mahmood S, Palladini G, Sanchorawala V, et al: Update on treatment of light chain amyloidosis. Haematologica 99:209-221, 2014

3. Merlini G, Wechalekar AD, Palladini G: Systemic light chain amyloidosis: An update for treating physicians. Blood 121:5124-5130, 2013

4. Gertz MA, Comenzo R, Falk RH, et al: Definition of organ involvement and treatment response in immunoglobulin light chain amyloidosis (AL): A consensus opinion from the 10th International Symposium on Amyloid and Amyloidosis, Tours, France, 18-22 April 2004. Am J Hematol 79:319-328, 2005

5. Palladini $G$, Hegenbart $U$, Milani $P$, et al: $A$ staging system for renal outcome and early markers of renal response to chemotherapy in $A L$ amyloidosis. Blood 124:2325-2332, 2014

6. Dinner S, Witteles W, Afghahi A, et al: Lenalidomide, melphalan and dexamethasone in a population of patients with immunoglobulin light chain amyloidosis with high rates of advanced cardiac involvement. Haematologica 98:1593-1599, 2013

7. National Comprehensive Cancer Network: NCCN clinical practice guidelines in oncology: Systemic light chain amyloidosis. Version 1. 2015. http:// www.nccn.org/professionals/physician_gls/pdf/amyloidosis.pdf

8. Wechalekar AD, Gillmore JD, Bird J, et al; BCSH Committee: Guidelines on the management of AL amyloidosis. Br J Haematol 168:186-206, 2015
9. Wall JS, Kennel SJ, Williams $A$, et al: $A L$ amyloid imaging and therapy with a monoclonal antibody to a cryptic epitope on amyloid fibrils. PLoS One 7:e52686, 2012

10. Comenzo RL, Reece $D$, Palladini $G$, et al: Consensus guidelines for the conduct and reporting of clinical trials in systemic light-chain amyloidosis. Leukemia 26:2317-2325, 2012

11. Wang W, Wang EQ, Balthasar JP: Monoclonal antibody pharmacokinetics and pharmacodynamics. Clin Pharmacol Ther 84:548-558, 2008

12. Pepys-Vered ME, Pepys MB: Targeted treatment for amyloidosis. Isr Med Assoc J 16:277-280, 2014

13. Merlini G, Seldin DC, Gertz MA: Amyloidosis: Pathogenesis and new therapeutic options. J Clin Oncol 29:1924-1933, 2011

14. Palladini G, Dispenzieri A, Gertz MA, et al: Validation of the criteria of response to treatment in AL amyloidosis. Blood 116:1364, 2010

15. Palladini G, Milani P, Foli $A$, et al: Oral melphalan and dexamethasone grants extended survival with minimal toxicity in AL amyloidosis: Long-term results of a risk-adapted approach. Haematologica 99:743-750, 2014

16. Wechalekar AD, Lachmann $\mathrm{HJ}$, Offer M, et al: Efficacy of bortezomib in systemic AL amyloidosis with relapsed/refractory clonal disease. Haematologica 93:295-298, 2008

17. Kastritis E, Anagnostopoulos A, Roussou M, et al: Treatment of light chain (AL) amyloidosis with the combination of bortezomib and dexamethasone. Haematologica 92:1351-1358, 2007

18. Kastritis $E$, Wechalekar AD, Dimopoulos MA, et al: Bortezomib with or without dexamethasone in primary systemic (light chain) amyloidosis. J Clin Oncol 28:1031-1037, 2010

19. Venner CP, Lane T, Foard $D$, et al: Cyclophosphamide, bortezomib, and dexamethasone therapy in AL amyloidosis is associated with high clonal response rates and prolonged progression-free survival. Blood 119:4387-4390, 2012

20. Kastritis $E$, Leleu $X$, Arnulf $B$, et al: $A$ randomized phase III trial of melphalan and dexamethasone (MDex) versus bortezomib, melphalan and dexamethasone (BMDex) for untreated patients with AL amyloidosis. Presented at the 56th ASH Annual Meeting and Exposition, San Francisco, CA, December 6, 2014

21. Cohen $A D$, Scott $E C$, Liedtke $M$, et al: A phase I dose-escalation study of carfilzomib in patients with previously-treated systemic light-chain (AL) amyloidosis. Presented at the 56th ASH Annual Meeting and Exposition, San Francisco, CA, December 6, 2015

22. Wechalekar AD, Schonland SO, Kastritis E, et al: A European collaborative study of treatment outcomes in 346 patients with cardiac stage III AL amyloidosis. Blood 121:3420-3427, 2013

23. Richards DB, Cookson LM, Berges AC, et al: Therapeutic clearance of amyloid by antibodies to serum amyloid P component. N Engl J Med 373: 1106-1114, 2015

24. Cox N, Pilling D, Gomer RH: Serum amyloid P: A systemic regulator of the innate immune response. J Leukoc Biol 96:739-743, 2014

25. Pilling $D$, Gomer RH: Persistent lung inflammation and fibrosis in serum amyloid $\mathrm{P}$ component (APCs-/-) knockout mice. PLoS One 9:e93730, 2014 
First-in-Human Phase I/II Study of NEOD001 in Patients With Light Chain Amyloidosis and Persistent Organ Dysfunction

The following represents disclosure information provided by authors of this manuscript. All relationships are considered compensated. Relationships are self-held unless noted. I = Immediate Family Member, Inst = My Institution. Relationships may not relate to the subject matter of this manuscript. For more information about ASCO's conflict of interest policy, please refer to www.asco.org/rwc or jco.ascopubs.org/site/ifc.

Morie A. Gertz

Honoraria: Celgene, Novartis, Millennium Pharmaceuticals, Med Learning Group, Research to Practice, Onyx Pharmaceuticals, Isis Pharmaceuticals, Sanofi, Prothena Therapeutics, GlaxoSmithKline Consulting or Advisory Role: Prothena Therapeutics

Travel, Accommodations, Expenses: Prothena Biosciences, Celgene, Novartis

\section{Heather Landau}

Honoraria: Takeda Pharmaceuticals, Spectrum Pharmaceuticals Consulting or Advisory Role: Onyx, Spectrum, Takeda, Prothena Therapeutics

Research Funding: Onyx Pharmaceuticals, Takeda Pharmaceuticals

Raymond L. Comenzo

Consulting or Advisory Role: Prothena Therapeutics, Janssen, Takeda Pharmaceuticals

Research Funding: Prothena Therapeutics, Takeda, Janssen

Pharmaceuticals, Teva Neuroscience

David Seldin

No relationship to disclose

Brendan Weiss

Consulting or Advisory Role: Janssen R\&D, Millennium,

GlaxoSmithKline

Research Funding: Prothena Therapeutics, Janssen Research \&

Development

Travel, Accommodations, Expenses: Janssen Research \& Development; Millennium Pharmaceuticals, Prothena Biosciences

\section{Jeffrey Zonder}

Consulting or Advisory Role: Array BioPharma, Celgene, Bristol-Myers Squibb, Prothena Therapeutics, Seattle Genetics

Research Funding: Celgene

\section{Giampaolo Merlini}

Honoraria: Millennium Pharmaceuticals, Takeda Pharmaceuticals, Pfizer Consulting or Advisory Role: Isis Pharmaceuticals

Speakers' Bureau: Janssen, Pfizer

Stefan Schönland

Honoraria: Janssen, Celgene

Consulting or Advisory Role: Prothena Therapeutics

Research Funding: Janssen, Celgene

Travel, Accommodations, Expenses: The Binding Site, Janssen, Medac

\section{Jackie Walling}

Stock or Other Ownership: Amgen, Biomarin

Consulting or Advisory Role: Prothena Therapeutics, Aduro, Oxigene, Upsher Smith, Corcept Therapeutics, KaloBios, Ultragenyx

Pharmaceuticals, NewGen Therapeutics, Crown Bioscience, Exelixis

Patents, Royalties, Other Intellectual Property: Upsher Smith, Amgen

Gene G. Kinney

Employment: Prothena Biosciences

Leadership: Prothena Biosciences

Stock or Other Ownership: Prothena Corporation, Neuroderm

Consulting or Advisory Role: Janssen

Patents, Royalties, Other Intellectual Property: Prothena Therapeutics

\section{Martin Koller}

Employment: Prothena Biosciences

Leadership: Prothena Biosciences

Stock or Other Ownership: Prothena Corporation

Travel, Accommodations, Expenses: Prothena Biosciences

Dale B. Schenk

Employment: Prothena Biosciences

Leadership: Prothena Biosciences

Stock or Other Ownership: Prothena Corporation

Patents, Royalties, Other Intellectual Property: Prothena Therapeutics Travel, Accommodations, Expenses: Prothena Biosciences

Spencer D. Guthrie

Employment: Prothena Biosciences

Leadership: Prothena Biosciences

Stock or Other Ownership: Prothena Corporation

Consulting or Advisory Role: Cerespir

\section{Michaela Liedtke}

Consulting or Advisory Role: Prothena Therapeutics, Amgen, Takeda Pharmaceuticals, Pfizer

Research Funding: Prothena Therapeutics, Amgen, Takeda

Pharmaceuticals, Pfizer, Celgene, Novartis, Bristol-Myers Squibb 


\section{Acknowledgment}

We thank all the patients and investigators who participated in this study. Medical editorial assistance was provided by David Gibson, CMPP, of ApotheCom, San Francisco, CA. This article is dedicated to the memory of David Seldin, MD, PhD, who died during the development of this manuscript.

\section{Appendix}

Previously determined definitions of systemic organ involvement for patients in the dose-escalation component: Cardiac involvement (mean left ventricular wall thickness of $>12 \mathrm{~mm}$ in the absence of other cardiac causes or elevated N-terminal pro-brain natriuretic peptide [NT-proBNP; $>332 \mathrm{ng} / \mathrm{L}$ ] in the absence of renal failure or atrial fibrillation) or renal involvement (proteinuria [predominantly albumin] $>0.5 \mathrm{~g} /$ day in a 24 -hour urine collection)

Definition of DLT: Any of the following regardless of relationship to NEOD001, unless clearly related to the underlying disease, and regardless of occurrence in the 28 days following NEOD001 administration: grade $\geq 3$ nonhematologic toxicity that has not responded to supportive therapy; grade $\geq 3$ neutropenia or thrombocytopenia; other grade $\geq 4$ hematologic toxicity; and any clinically significant occurrence thought to pose undue safety risk for patients

Definition of cardiac response: Cardiac response was defined as a $>30 \%$ and $>300 \mathrm{pg} / \mathrm{mL}$ NT-proBNP decrease, and cardiac progression was defined as an increase of the same magnitude. Of note, patients with progressively worsening renal function (defined as worsening of creatinine or creatinine clearance $>25 \%$ over baseline) could not be scored for NT-proBNP progression. Stable cardiac response was defined in patients who were not NT-proBNP responders or progressors. In addition, a decrease in the New York Heart Association (NYHA) class of two or greater was considered a response for patients with baseline NYHA class 3 or 4.

Definition of renal response: Renal response was defined as a $\geq 30 \%$ decrease (or $<0.5 \mathrm{~g} /$ day) of 24-hour urine protein, where urine protein must be greater than $0.5 \mathrm{~g}$ /day before treatment and eGFR must not worsen by $25 \%$ over baseline

\begin{tabular}{|lcc|}
\hline Table A1. NT-proBNP Did Not Decline Before NEOD001 & \begin{tabular}{c} 
Administration \\
\hline Multiple Baseline NT-proBNP Measurements \\
Before NEOD001 Treatment
\end{tabular} & $\begin{array}{c}\text { NT-proBNP, } \\
\mathrm{pg} / \mathrm{mL}\end{array}$ \\
\hline Mean of all patients before NEOD001 treatment & 10 & 1,468 \\
Measurement 1 & 10 & 1,611 \\
Measurement 2 & 4 & +143 \\
Difference & 4 & 2,249 \\
Mean of cardiac responders before NEOD001 treatment & & \\
Measurement 1 & & +116 \\
Measurement 2 & 465 \\
Difference & & \\
\hline Abbreviation: NT-proBNP, N-terminal pro-brain natriuretic peptide. & \\
\hline
\end{tabular}

